\title{
A judicialização da competição política: o TSE e as coligações eleitorais*
}

\author{
Vitor Marchetti \\ Departamento de Política da \\ Pontifícia Universidade Católica - SP \\ Rafael Cortez \\ Departamento de Ciência Política da \\ Universidade de São Paulo
}

\begin{abstract}
Resumo: Há uma extensa literatura que se debruça sobre os efeitos do poder judiciário no funcionamento dos sistemas políticos. Estaríamos assistindo à judicialização da política? $\mathrm{O}$ argumento apresentado é que o entendimento acerca da influência do direito na dinâmica dos sistemas políticos supõe uma noção mais ampla sobre o lócus e o momento em que ocorre sua interferência no funcionamento das democracias contemporâneas. A proposta é discutir a judicialização no que diz respeito à definição das regras da competição político-eleitoral. Para isso, analisaremos a decisão do TSE (Tribunal Superior Eleitoral) referente à verticalização das coligações. O argumento é que o TSE não apenas interpretou uma legislação, mas também estabeleceu um novo regulamento no lugar do poder legislativo. Nossa análise demonstra que a regulamentação das coligações eleitorais é fruto de interação estratégica entre o TSE e o poder legislativo.
\end{abstract}

Palavras-chaves: judicialização da política; coligações eleitorais; poder judiciário; verticalização

\begin{abstract}
There is an extensive literature to study the effects of the judiciary power on how political systems work. Is there a judicialization of politics? Our point is that the answer to that question is connected to theoretical questions about the ways to prove and where scholars should look in order to detect the effect of judiciary in democratic systems. In this work we analyze the judicialization of politics under the perspective of the definition of the rules of electoral competition. In order to prove our argument, this article studies how TSE (brazilian judiciary court) rules coalitions in Brazil's political system, known as "verticalização" _the uniformity of party coalitions at state and federal levels. Our case study shows that TSE, in fact, not only interprets the law but, actually, establishes rules, taking the place of the legislative body _which, in turn, made another move. The analysis suggests that the question of judiciary of politics should be seen as an strategic interaction between the two powers.
\end{abstract}

Keywords: judicialization of politics; electoral coalition, Judiciary Power; "verticalização"

\footnotetext{
* Esta é uma versão do paper apresentado no XXXI encontro da ANPOCS no ST: "Controvérsias Conceituais da Democracia Contemporânea: Teoria e Empiria". Os autores agradecem aos colegas que debateram esse trabalho, especialmente a Matthew Taylor, Rogério Arantes e Cláudio Couto. Agradecemos ainda ao parecerista anônimo de Opinião Pública pelos valiosos comentários e sugestões. Os possíveis equívocos remanescentes são de nossa exclusiva responsabilidade.
} 


\section{Apresentação}

O papel das instituições judiciárias no processo político brasileiro tem sido alvo de análises e interpretações por parte da ciência política, sobretudo a partir do início da década de 1990. Essa crescente atenção para a interseção entre a política e o direito é decorrente de um fenômeno histórico característico das sociedades ocidentais, a saber: a crescente influência do poder judiciário na formatação das políticas públicas, bem como a proteção de direitos individuais e coletivos (TATE e VALLINDER, 1995). Essa tendência comum aos diferentes sistemas políticos é acentuada devido ao recente processo de democratização, no caso brasileiro, do sistema político brasileiro e da influência da Constituição de 1988 nas relações políticas, sociais e econômicas do país.

A literatura brasileira tem ressaltado a mudança de valores e da tradição jurídica expressa na nova carta constitucional. As instituições judiciárias brasileiras no período democrático recente estariam informadas por uma tradição "republicana", na qual o papel central do poder judiciário não seria somente o de garantir os direitos individuais típicos do liberalismo político (liberdades negativas) mas também ser um agente na conquista dos direitos coletivos e difusos (ARANTES, 2002, 2005; ARANTES e KERCHE, 1999; VIANNA et al, 1999; KOERNER, 2005).

Essa "função social" do poder judiciário bem como a democratização do acesso à justiça, levadas a cabo pela Constituição de 1988, estariam materializadas fundamentalmente nos mecanismos descentralizados para o controle social e político da constitucionalidade dos atos normativos por meio da ampliação dos agentes legitimados a propor uma ADIN (Ação Direta de Inconstitucionalidade); no mecanismo da ação civil pública, bem como no papel exercido pelos tribunais especiais ${ }^{1}$.

Arantes (2002 e 2005) argumenta que o novo papel das instituições judiciárias seria decorrente de uma reconstrução institucional, especialmente do Ministério Público, com um diagnóstico que tem como base a incapacidade da sociedade civil de se organizar espontaneamente, bem como a incapacidade dos mecanismos representativos de garantirem os direitos individuais e coletivos na sociedade. Nesse sentido, haveria um deslocamento do lócus de conquista de direitos dos canais político-partidários para a arena judicial.

Em contrapartida, para Vianna et al (1999), o processo de judicialização da política seria expressão da complementaridade da democracia participativa, ainda que organizado pelas instituições judiciais e os mecanismos clássicos da

\footnotetext{
${ }_{1}^{1}$ Para uma análise mais aprofundada acerca do controle da constitucionalidade das leis, ver Vianna et al, 1999; Marchetti, 2004; Carvalho, 2004. Para uma discussão acerca das ações civis públicas, ver Arantes, 2002; Vianna e Burgos, 2006.
} 
representação. Nesse sentido, o processo de democratização seria aprofundado por meio da combinação dos princípios plebiscitário e funcional na salvaguarda dos direitos dos diferentes grupos sociais.

A problemática central dessa crescente literatura é identificar se esse "novo" papel do poder judiciário, bem como a democratização do acesso, teria como consequência a judicialização do processo político brasileiro (CASTRO, 1997; VIANNA et al, 1999; ARANTES e KERCHE, 1999; CARVALHO e OLIVEIRA, 2002; KOERNER, 2005; OLIVEIRA, 2005; TAYLOR, 2006, 2007a). Em outras palavras, qual seria o papel do poder judiciário para o funcionamento do nosso sistema político?

Grosso modo, existem dois diagnósticos distintos. De um lado, há uma série de trabalhos que argumentam que o crescente protagonismo das instituições judiciais na garantia dos direitos para indivíduos e agrupamentos coletivos deslocaria parte do conflito político para o interior das cortes (ARANTES, 2002, 2005; VIANNA et al, 1999; ARANTES e KERCHE, 1999; TAYLOR 2006, 2007a). Outros, porém, argumentam que, a despeito da crescente demanda, o judiciário toma decisões de forma a respeitar a vontade majoritária - isto é, não haveria diferença de preferência entre os atores no que diz respeito às políticas públicas (CASTRO, 1997; CARVALHO e OLIVEIRA, 2002; CARVALHO, 2004; OLIVEIRA, 2005; KOERNER, 2005).

Nossa leitura é que o diagnóstico da existência ou não de um processo de judicialização da política decorre das diferenças conceituais que informam os diferentes trabalhos. O argumento negativo sobre o processo de judicialização da política no caso brasileiro está apoiado no conceito empregado por Tate e Vallinder (1995). Na visão dos autores, a judicialização do conflito político ocorre somente quando há uma diversidade de preferências no que diz respeito ao desenho das políticas públicas, isto é, ao resultado final do processo. Essa é a motivação analítica para a escolha do STF como objeto primordial dessa literatura.

O objetivo deste artigo é oferecer um foco distinto para a discussão da relação entre direito e política. A proposta é discutir a judicialização no que diz respeito à definição das regras da competição político-eleitoral e não na formulação de políticas públicas. Para isso, analisaremos a decisão do TSE (Tribunal Superior Eleitoral) referente à regulamentação das coligações eleitorais, no que ficou conhecido na agenda pública como "verticalização" das coligações.

O argumento apresentado é que o entendimento acerca da influência do direito na dinâmica dos sistemas políticos supõe uma noção mais ampla sobre o lócus e o momento em que ocorre a interferência do poder judiciário no funcionamento das democracias contemporâneas. Em outros termos, argumentamos que a judicialização da política não ocorre necessariamente no 
resultado final do processo, mas pode ocorrer no momento da definição das regras do jogo que constrangerão atores nas disputas políticas (FEREJOHN, 2002).

Nossa intenção é demonstrar como o TSE, com sua interpretação da legislação, mudou o padrão de competição eleitoral do Brasil no que diz respeito à dimensão das coligações eleitorais. Como veremos, a interpretação do TSE acerca da verticalização das coligações eleitorais resultou na aprovação de uma emenda constitucional por parte dos parlamentares com objetivo de restringir a influência do TSE na definição das regras do jogo político-partidário.

Couto e Arantes (2006) classificaram os dispositivos presentes na constituição brasileira em "polity" (normas constitucionais), "politics" (competição política) e "policies" (políticas públicas). Ao menos na análise desse debate sobre a verticalização das coligações, podemos dizer que estamos diante de um caso de "politic" que foi transformada em "polity".

A reação do poder legislativo à interpretação do TSE mostra que o judiciário enfrenta dilemas estratégicos em sua relação com os demais poderes que compõem o arcabouço institucional brasileiro. Trata-se de uma problemática relativa à garantia de tornar efetivas suas decisões. Taylor (2007) argumenta que há um espaço para independência efetiva de um órgão judicial que varia conforme o posicionamento das preferências dos atores e o custo de "derrubada" da decisão judicial. Se o poder judiciário tomasse uma decisão contrária a um ator político externo e, por sua vez, esse fosse capaz de superar os custos de derrubada de uma lei, não haveria independência de aspectos constitucionais. Essa foi a dinâmica que ocorreu com a regulamentação das coligações eleitorais. O TSE teve sua decisão derrubada por ferir as preferências da maioria legislativa.

Contrariamente ao esperado pela literatura (SADEK, 1995, p. 63), mostramos que o processo de intervenção do TSE na regulação da competição política não se deve necessariamente à instabilidade da composição da corte, tampouco da legislação eleitoral. Na verdade, mostramos que há uma visão normativa por parte do órgão acerca do suposto "bom" funcionamento do sistema político brasileiro.

Nosso ponto de partida é a constatação de um suposto razoavelmente óbvio, mas de implicações analíticas importantes, a saber: o conceito de judicialização significa, no limite, que o judiciário exerce poder sobre o processo político. Assim, este artigo inicia com a discussão sobre a noção de poder implícita nas diferentes abordagens da judicialização, de forma a justificar analiticamente a escolha do TSE como objeto de análise. Essa é a tarefa da primeira seção. A segunda seção analisa o conflito em torno da definição das regras acerca do padrão das coligações eleitorais. A ideia é mostrar as bases normativas da interpretação que o tribunal deu à legislação partidário-eleitoral no tocante à atuação dos partidos no momento da competição eleitoral bem como os efeitos desse novo padrão normativo na 
dinâmica política.

Por fim, a conclusão resume os achados centrais e lança luz sobre futura agenda de pesquisa com a inclusão do TSE para compreender melhor a relação entre direito e política.

\section{Conceito de poder e a judicialização da política}

O debate sobre a judicialização da política é uma discussão sobre perspectivas conceituais e estratégias analíticas visando à mensuração do poder judiciário na determinação da forma e dos resultados do processo político. Se isso é verdade, o diagnóstico dos diferentes trabalhos que tratam da relação entre direito e política resulta parcialmente dessas diferenças na forma de abordagem do fenômeno. Nossa intenção é revisitar os termos das contendas entre os teóricos pluralistas e os elitistas, tendo como foco suas respectivas estratégias de análise, e demonstrar como essas diferentes perspectivas aparecem no debate da judicialização do poder².

O poder nas sociedades estaria distribuído de forma a preservar o princípio igualitário fundador das sociedades democráticas? Essa é a questão central do debate entre essas correntes. A resposta elitista a essa questão é negativa. A ideia é que haveria uma estrutura de poder na sociedade, fruto da sua distribuição desigual de poder entre os atores sociais. O argumento é que essa estrutura de poder seria decorrente do poder "posicional" dos indivíduos no interior da sociedade e estaria concentrado em determinadas posições-chave nos diferentes subsistemas sociais (MILLS, 1956).

A crítica pluralista é que os resultados encontrados pelos teóricos das elites não seriam decorrentes de métodos rigorosamente científicos e de observações empíricas das relações de poder entre os diferentes grupos sociais. Dahl (1958) argumenta que não é correto inferir, tampouco quantificar, relações de poder em decorrência de posição social ou de reputação no interior da coletividade, mas é necessário mensurar o exercício efetivo desse poder. Trata-se, na verdade, de um deslocamento do foco de uma suposta origem do poder social para um olhar sobre o processo decisório, com o objetivo de identificar em que medida as preferências dessa elite do poder estariam presentes nos resultados finais do processo decisório.

Grosso modo, seriam quatro as etapas fundamentais de uma pesquisa: seleção de decisões relevantes; identificação dos atores centrais presentes no processo decisório; investigação do comportamento observado desses atores e análise dos resultados finais do conflito.

2 Para uma interessante análise do debate pluralista e elitista, ver MIGUEL (2003). 
Nesse momento, nosso objetivo é relacionar a metodologia pluralista a uma concepção específica do significado de poder. A definição de poder que informa os trabalhos dos pluralistas está relacionada com alterações nos comportamentos dos autores (DAHL, 1957, p. 203, apud RIKER, 1964, p.342).

De acordo com Riker (1964), o suposto da concepção de Dahl é a ideia de que o poder é relacional e diádico. Em outros termos, as relações de poder se estabelecem entre pares de indivíduos em interação, um buscando alterar o comportamento do outro. Para haver relações de poder é necessário, portanto, que existam preferências distintas entre os atores participantes de determinado conflito.

Segundo Bachrach e Baratz (1962), a metodologia pluralista teria acarretado ganhos analíticos em relação às abordagens elitistas ao buscar evidências sistemáticas das relações de poder. Contudo, ela sofre de sérias limitações decorrentes da ênfase em decisões "importantes", bem como no resultado final e "observável" da disputa política. O pluralismo teria deixado de lado o que os autores denominaram como "segunda face do poder".

Esses dois traços da metodologia pluralista, quais sejam, definir o importante e considerar apenas o observável, impediriam a identificação do processo de "mobilization of bias", que diz respeito ao fato de que existem valores em procedimentos e instituições que limitam as escolhas e as preferências dos atores. A intuição do argumento é que as definições dessas regras e procedimentos são um lócus para as disputas políticas e importantes para o entendimento das relações de poder, afinal, eles não são neutros e tenderiam a favorecer alguns grupos vis-à-vis os demais participantes do processo. Trata-se da discussão sobre os efeitos do poder de agenda na relação entre atores sociais.

Essa etapa do processo político seria fundamental para entender o resultado final. A ideia é que batalhas políticas relevantes não precisam necessariamente ocorrer no momento do processo decisório. O resultado final de um processo pode refletir disputas políticas não necessariamente em pontos substantivos do "issue" em questão, mas desse viés presente nas regras que regulam a atividade política.

Se o olhar institucionalista (MARCH e OLSEN, 1984), a partir do qual os resultados não podem ser inferidos diretamente a partir das preferências dos atores, faz sentido, tentativas de mensurar as relações de poder deveriam levar em consideração como as instituições enviesam os resultados finais produzindo, no limite, situações de "não decisão"3.

A "segunda face do poder" guarda proximidade com a noção de poder presente em March (1957). A intuição de sua definição de poder é que esse é um atributo relativo à capacidade dos atores de restringir os resultados possíveis. Ora,

3 Termo utilizado por Bachrach e Baratz (1962) para expressar os limites da abordagem "decisionista" típica do pluralismo. Uma situação de "não decisão" seria decorrente de correlação de poder entre os atores no jogo político. 
essa noção nos leva a deslocar o foco do comportamento observável dos atores para as regras e os procedimentos da disputa política.

Para os nossos fins, a influência do poder judiciário pode não se dar no resultado final do processo político, ou seja, nas políticas públicas, mas na definição das regras do jogo que balizam a disputa política. Nossa leitura é que, sendo a disputa política um processo, o momento escolhido para mensurar relações de poder entre os atores é crucial para o entendimento desse processo.

A discussão acerca das relações entre direito e política no Brasil foi decorrente da definição proposta por Tate e Vallinder (1995). O argumento dos autores é que tal conceito de judicialização da política enfatiza as possíveis alterações propostas pelo poder judiciário no desenho das políticas públicas. Em outros termos, informados pelo papel que as instituições judiciais tiveram no interior da tradição liberal, qual seja, garantia do equilíbrio entre os poderes pelo controle da vontade da maioria expressa no parlamento.

Nesse sentido, a judicialização da política seria um fenômeno decorrente do controle da vontade majoritária. Segundo Vallinder, significaria um fenômeno no qual ocorreriam expansão do poder decisório das cortes e utilização dos métodos judiciais fora do âmbito das cortes (VALLINDER, 1995, p.13).

A primeira dimensão do processo de aumento da influência das instituições judiciais na política ("from without") expressaria-se-ia na discussão sobre o controle de constitucionalidade da produção normativa de um sistema político. A literatura brasileira debruçou-se fundamentalmente nessa perspectiva. A agenda de pesquisa que serviu como motor para esse campo de estudo buscou mensurar em que medida o STF (Supremo Tribunal Federal) agiria como um poder que se contraporia à vontade majoritária formada no interior das instituições político-representativas (CASTRO, 1997; WERNECK et al, 1999; CARVALHO e OLIVEIRA, 2002; MARCHETTI, 2004; CARVALHO, 2004; KOERNER, 2005; OLIVEIRA, 2005).

É importante destacar que essa definição de judicialização da política é de natureza semelhante à da metodologia pluralista. A ideia é que os desenhos de pesquisa deveriam focar-se em questões com conflito explícito entre preferências, tendo como foco o resultado final do processo decisório sobre políticas públicas. Assim, só comprovaríamos a invasão do espaço da política pelo direito se pudéssemos mensurar alteração no desenho das políticas.

Não há espaço para identificar relações de poder entre as instituições representativas e judiciárias durante o processo político, isto é, no seu aspecto procedimental. As palavras de Tate expressam a associação entre esse conceito de judicialização e o método pluralista, revelando uma crítica ao conceito de "não decisão" de Bachrach e Baratz (1962): 
“Em condições favoráveis, a judicialização se desenvolve somente quando os juízes decidem (1) participar no processo de decisão que poderia ser de responsabilidade para sábia ou tola vontade de outras instituições e (2) substituir as soluções políticas dessas outras instituições.[...] Mas "a judicialização da política" implica em um papel mais positivo do que aquele presente na "não decisão judicial" (TATE, 1995, p. 33, grifo nosso).

Vejamos como essa perspectiva está por trás dos diagnósticos sobre o papel do poder judiciário na experiência democrática brasileira. Castro (1997) argumenta que o STF não tem exercido seu papel de guardião dos direitos individuais em contraposição às iniciativas governamentais. $O$ argumento é que o STF tem julgado em favor do governo e não dos atores privados, com exceção das políticas tributárias.

Nessa mesma linha de argumentação, Koerner (2005) afirma que, no exercício do papel do judiciário, há um certo descompasso entre as preocupações do constituinte e o "novo" contexto econômico e político no qual está inserida a Constituição de 1988. Dessa forma, a construção de um regime jurisprudencial do STF, no que diz respeito ao controle de constitucionalidade, deu-se no sentido de preservação e de interpretação de seu aspecto procedimental, isto é, limitando a análise formal dos requerimentos de constitucionalidade, evitando alterar a vontade majoritária na definição do desenho do ordenamento estatal que estaria sendo proposta com a "onda" de alterações constitucionais.

Carvalho (2004) argumenta que a simples explosão de processos contestando a atividade normativa governamental, conforme constatação de Vianna et al (1999), seria insuficiente para caracterizar o quadro brasileiro como um sistema em que o judiciário de fato controla os outros poderes. A despeito de as condições para o processo de intervenção do direito na política estarem presentes, não haveria, no caso brasileiro, disposição dos juízes em intervir no processo de produção de políticas públicas. Essa falta de "ímpeto" intervencionista estaria expresso na baixas taxas de resposta do STF aos questionamentos de atores sociais e políticos relativos à constitucionalidade das leis.

O conceito de "ciclo da judicialização da política" (OLIVEIRA, 2005) expressa com clareza a importância do processo decisório final como momento essencial no debate entre política e direito. Esse ciclo seria composto por três etapas. A primeira diz respeito ao exponencial aumento do acionamento das instituições judiciais. A segunda etapa corresponde ao julgamento de liminares e, por fim, o julgamento do mérito da ação (OLIVEIRA, 2005, p. 560). A conclusão da autora é que os membros do judiciário brasileiro não apresentaram "preferência judicial por políticas públicas". 
Esse foco no resultado do processo político e no controle da vontade da maioria é o que explicaria a atenção dada pela literatura nacional ao STF como órgão central no desenvolvimento das pesquisas nessa área.

O diagnóstico negativista quanto à existência de uma judicialização efetiva do sistema político brasileiro é, em parte, determinado pelas questões conceituais e metodológicas levantadas anteriormente. A essa noção mais estreita da judicialização da política podemos contrapor uma definição de escopo mais amplo, que visualiza a interferência do direito na política em diferentes momentos do processo político.

Os trabalhos que de alguma forma descolaram-se das amarras da concepção presente no trabalho de Tate e Vallinder identificaram no caso brasileiro efeitos decorrentes da judicialização no momento da implementação das políticas públicas (TAYLOR, 2006 e 2007), no efeito fragmentador do sistema político brasileiro (KERCHE e ARANTES, 1999; TAYLOR, 2006) ou na garantia dos direitos individuais e coletivos (ARANTES, 2002; VIANNA et al, 1999).

Nosso suposto é que, além das implicações substantivas no desenho das políticas públicas e da garantia dos direitos individuais controlando possíveis abusos da vontade majoritária, a influência das instituições judiciais pode ser percebida nos procedimentos relativos à própria competição política. Nas palavras de Ferejohn:

"Podemos distinguir pelo menos três formas pelas quais as cortes podem
exercer novos e importantes papéis relativos às legislaturas. Primeiro, as
cortes podem limitar e regular o exercício da autoridade parlamentar
impondo limites substantivos no poder das instituições legislativas.
Segundo, as cortes têm cada vez mais se tornado espaço para decisão de
políticas. Terceiro, as cortes têm cada vez mais regulado a conduta da atividade política - seja praticada nas legislaturas, agências ou no eleitorado - construindo padrões de conduta aceitáveis para grupos de interesse, partidos políticos e representantes eleitos ou indicados" (FEREJOHN, 2002, p.41, grifo nosso).

Seguindo a sugestão do autor, nossa análise se debruçará sobre os efeitos dos órgãos judiciais na definição das regras que regulam a atividade política. Esse efeitos são ainda mais evidentes no Brasil. Afinal, como demonstrou Marchetti (2008b), nosso desenho institucional para a regulação da competição política é bastante concentrado no judiciário.

Nossa discussão focaliza o TSE (Tribunal Superior Eleitoral), que é responsável pela definição da estrutura normativa do momento eleitoral. Do ponto de vista analítico, o objetivo é buscar entender relações de poder no momento 
anterior ao processo de formulação de políticas públicas, de forma a escapar dos limites analíticos da face "visível" na barganha entre os poderes. Nos preocupamos com a decisão acerca da regulação da formação de coligações eleitorais e, assim, dar nossa contribuição para essa área de pesquisa.

\section{O TSE e a "verticalização" das coligações}

O tema da simetria entre as coligações partidárias nas disputas estaduais e nacionais é emblemático para o debate, ainda incipiente, sobre a instabilidade da legislação eleitoral desde a redemocratização e o impacto que as decisões do TSE podem ter sobre a competição político-partidária.

A simetria das coligações partidárias - ou regra da verticalização, como o tema ficou conhecido - estabeleceu limites mais rígidos para a formação de alianças em eleições em que simultaneamente estivessem em disputa cargos majoritários e proporcionais nos níveis federais e estaduais.

A decisão do TSE que iniciou a polêmica foi tomada em fevereiro de 2002, ano da eleição presidencial que elegeria o sucessor de Fernando Henrique Cardoso (FHC), na qual estavam em jogo os rumos das reformas nas instituições do Estado e na economia do país e, por isso mesmo, foi marcada por expectativas e tensões dos diversos setores da economia e da sociedade civil.

Vale um brevíssimo panorama de como as regras do jogo eleitoral para a formação de coligações foram definidas nas eleições anteriores, as de 1994 e $1998^{4}$.

Nas eleições de 1994, sob a regência da lei 8.713/93, foi facultado aos partidos celebrar coligações para as eleições majoritárias e proporcionais desde que não fossem diferentes dentro de uma "mesma circunscrição". Num país como o Brasil, em que o pacto federativo é variável fundamental para disputas políticopartidárias, definir com precisão se a expressão do texto legal "mesma circunscrição" refere-se aos limites subnacionais ou ao nacional é definir como os partidos distribuirão forças e recursos.

Para que não restassem dúvidas a respeito, o TSE emitiu uma resolução que, dentre inúmeros procedimentos e providências, acrescentou um termo à lei, definindo que "mesma circunscrição" deveria ser entendida como "dentro do mesmo estado".

\footnotetext{
${ }^{4}$ A análise de eleições anteriores é feita a partir de 1994 pois é somente a partir daí que temos eleições proporcionais e majoritárias simultâneas para os cargos nacionais e estaduais.
} 
Em resposta a uma consulta ${ }^{5}$, o tribunal decidiu também que a simetria exigida pela lei impedia os partidos integrantes de uma mesma aliança majoritária de formar uma outra aliança para as eleições proporcionais, ainda que com partidos não concorrentes nas eleições majoritárias. Se A, B, C e D apoiassem um candidato a governador, não poderiam formar duas alianças com, por exemplo, A e $\mathrm{B}$ e outra com C e D, para as eleições proporcionais do mesmo estado. Os partidos até poderiam romper a coligação majoritária para a disputa proporcional, entretanto, não poderiam formar uma coligação diferente da majoritária, devendo concorrer isoladamente.

Entre a vitória de FHC em 1994 e as eleições em 1998, o Congresso nacional aprovou a lei $n^{\circ}$ 9504/97, que ficou conhecida como lei das eleições. Em grande medida, a nova lei veio garantir alguns pontos já pacificados pela jurisprudência do TSE, consolidar algumas modificações já feitas no antigo código e conferir segurança jurídica para as novas regulamentações constitucionais, como por exemplo, a possibilidade de reeleição nas eleições majoritárias.

Quanto ao tema das coligações partidárias, a lei de 1997 reformou a decisão judicial anterior, liberando os partidos coligados para o pleito majoritário a formarem alianças distintas para os pleitos proporcionais. Dessa forma, se A, B, C e $D$ formassem uma coligação para a eleição para governador, poderiam formar entre si outras alianças para as eleições proporcionais.

Para as eleições seguintes, em 2002, não havia grandes novidades do ponto de vista legal. A lei das eleições de 1997 vinha sofrendo alguns ajustes, mas nada substancial para as disputas político-partidárias.

Entretanto, em agosto de 2001, o PDT (Partido Democrático Trabalhista) fez uma consulta ao TSE com a seguinte pergunta: "pode um determinado partido político (partido A) celebrar coligação, para eleição de Presidente da República, com alguns outros partidos (partido B, C e D) e, ao mesmo tempo, celebrar coligação com terceiros partidos ( $E, F$ e $G$, que também possuem candidato à Presidência da República) visando à eleição de Governador de Estado da Federação?". Em outros termos, queriam saber se era possível coligar-se nos estados com partidos que estivessem disputando as eleições presidenciais como adversários.

Depois de alguns meses de debate entre os sete ministros, cinco responderam negativamente e dois positivamente à consulta, obrigando os partidos políticos a formarem alianças estaduais simétricas em relação às alianças nacionais.

\footnotetext{
${ }^{5}$ A consulta está prevista no artigo 23 do CE. Quando o TSE a responde, não produz efeitos jurídicos. A pergunta é feita em tese e a resposta também é dada em tese. Entretanto, principalmente em ano eleitoral, essas respostas são incorporadas pelas Instruções que o TSE publica para regular o processo eleitoral.
} 
A composição ${ }^{6}$ da corte eleitoral nesse momento tinha uma característica peculiar: parte relevante de seus membros tinha experiência com o processo eleitoral, ou porque tinha passagem pela justiça eleitoral ou pela vida políticopartidária?.

Dessa corte não se pode dizer que não havia uma visão clara do padrão de coligações vigente e do impacto que a decisão da verticalização produziria sobre o jogo político-partidário.

Os argumentos que fundamentaram a decisão do TSE pela verticalização sob o ponto de vista jurídico estavam sustentados em dois pontos: 1) interpretação do termo "mesma circunscrição" do artigo $6^{\circ}$ da lei 9504/97 e 2) interpretação do texto constitucional que definia que os partidos deveriam ter "caráter nacional". Mas, para além das fundamentações legais, há uma discussão sobre o papel do TSE e um posicionamento sobre a qualidade da democracia brasileira por parte dos ministros, que revelam mais da essência da decisão tomada.

Quanto ao primeiro ponto, numa suposição lógica do que a vontade do legislador tentou expressar na lei das eleições em 1997, Jobim defendeu que se a expressão "mesma circunscrição" se referisse apenas ao estado, ela perderia sentido. Afinal, alianças para governador, senador, deputados estaduais e federais só podem ser dentro de um mesmo estado, pois o distrito eleitoral dessas eleições é estadual. Sendo assim, não haveria propósito em dizer que as alianças devem ser realizadas dentro de uma mesma circunscrição. Mas, como definiu o ministro, "a lei não tem expressões inúteis". Se a expressão é inútil para se referir ao estado e não há expressões inúteis na lei, a expressão só pode estar se referindo ao âmbito nacional - só assim ela seria útil.

O segundo ponto do debate no plenário do TSE passou por uma interpretação do texto constitucional. Em seu artigo 17, inciso I, a Constituição Federal define que os partidos políticos brasileiros devem ter "caráter nacional". Na interpretação de Jobim, isso significou que as alianças feitas em âmbito nacional deveriam condicionar as alianças estaduais.

Assumimos que a argumentação jurídica não revela a essência dessa decisão ${ }^{8}$. O problema que norteava o debate era, em verdade, outro: qual é o papel do TSE na democracia brasileira? A análise desse debate permite identificar dois posicionamentos. De um lado, a defesa de um comportamento mais moderado da

\footnotetext{
${ }^{6}$ O TSE compõe-se da seguinte maneira: a) três juízes dentre os ministros do STF, b) dois juízes dentre os ministros do STJ e c) dois advogados indicados pelo STF.

7 Por exemplo, o ministro Sepúlveda Pertence teve sua primeira participação no TSE em maio de 1990, tendo atuado por quatro biênios como ministro titular. Já o ministro Nelson Jobim contava com uma experiência também na prática político-partidária, pois já fora deputado constituinte e ministro de estado.

${ }^{8}$ Aliás, há inúmeros contra-argumentos jurídicos que também serviriam para a interpretação dos termos "mesma circunscrição" e "caráter nacional". A tese derrotada do ministro Pertence na CTA 715 trouxe alguma dessas outras possíveis interpretações
} 
corte eleitoral, defendendo o exercício de uma função apenas operacional. De outro, a defesa de um comportamento mais arrojado, capaz de diagnosticar problemas na democracia representativa e promover os ajustes necessários.

$\mathrm{Na}$ interpretação derrotada no plenário, o ministro Sepúlveda Pertence trouxe o tema da autonomia partidária garantida pela Constituição federal. Sua preocupação em relação à decisão que se tomava ali era a de que, ao ser mais arrojado, o tribunal limitasse essa autonomia, impondo um padrão estranho à prática partidária.

O risco era que o tribunal avançasse sobre terrenos em que não seria prudente avançar. Essa decisão não seria, assim, uma mera interpretação do texto legal, muito menos uma iniciativa para garantir o bom cumprimento das obrigações legais. Seria, de fato, uma produção legislativa da justiça eleitoral, fruto de uma, na definição do próprio ministro, "interpretação voluntarista da lei em que a vontade dos juízes substitui a opção do legislador".

A maioria dos ministros não explicitou seu voluntarismo nem defendeu abertamente uma ação mais arrojada do TSE. Mas, ao analisarmos alguns dos argumentos na interpretação jurídica da questão, notamos quais princípios guiaram os ministros na interpretação vencedora.

A resposta do ministro Jobim, que serviu de parâmetro para a maioria do plenário, defendia que a assimetria das coligações contribuía apenas para favorecer interesses regionais e esvaziar a força nacional dos partidos políticos. Em sua visão, partidos nacionais são uma garantia de consistência política, e a consistência política seria um resultado da obrigatoriedade da simetria das coligações partidárias estaduais em relação às alianças nacionais.

A resposta arrojada que ali se formulava não serviria apenas para dirimir uma pequena dúvida de procedimentos. O que ali se construía era algo maior. Buscavam-se respostas para atender questionamentos históricos, acadêmicos e institucionais: qual é a qualidade dos partidos políticos na democracia brasileira?

Citando e aderindo aos diagnósticos de Mainwaring (2001), segundo os quais os partidos políticos no Brasil não têm força nacional e são, na verdade, uma federação de partidos estaduais sem penetração nacional, o ministro acreditava na força do TSE para corrigir essas características. Daí a obrigatoriedade da simetria das coligações estaduais com a nacional. Há aqui o diagnóstico e o remédio:

"Esse é o caminho para o fortalecimento dos partidos, como instrumentos nacionais da democracia brasileira. É essa a opção do sistema legal brasileiro, que luta contra os vícios regionalistas que vêm do início da República. (...) A autonomia dos partidos restringe-se à definição de "sua estrutura interna, organização e funcionamento" (CF, art. 17, §1ํ). Não têm 
eles o poder de dispor sobre o "caráter nacional" exigido pela Constituição

e pela lei" (ministro Nelson Jobim, consulta 715/02).

Seguindo essa linha, o TSE decidiu que atender a interesses regionais implicaria em atender a interesses de conveniência, e que somente partidos fortes em âmbito nacional poderiam atender aos interesses da nação e do eleitorado, e assim consolidar a democracia no país (mesmo que para isso fosse preciso contrariar práticas e aprendizados anteriores, impondo a mudança pela via judicial). Tratava-se de um sinal claro de que, se o sistema político tem comportamentos pouco adequados para o fortalecimento da democracia, é preciso, por meio de uma obrigação pedagógica, ensinar-Ihes modos mais adequados aos regimes democráticos. Para a maioria do TSE em 2002, o fato de a prática partidária em coligações estar muito distante do modelo de partidos nacionalmente fortes reforçava a urgência de reformar as regras do jogo.

O Gráfico 1 mostra o índice de simetria de cada partido nas duas eleições que antecederam a decisão de 2002 pela verticalização. Os partidos analisados são apenas os que disputaram as eleições majoritárias para presidente e governadores de estado. O objetivo é mostrar como a decisão do TSE para as eleições de 2002 estabeleceu um padrão de coligações completamente distante da realidade da maioria dos partidos até aquele momento. 
GRÁFICO 1

Nível de congruência entre as coligações estaduais e nacionais nas eleições de 1994 e 1998.

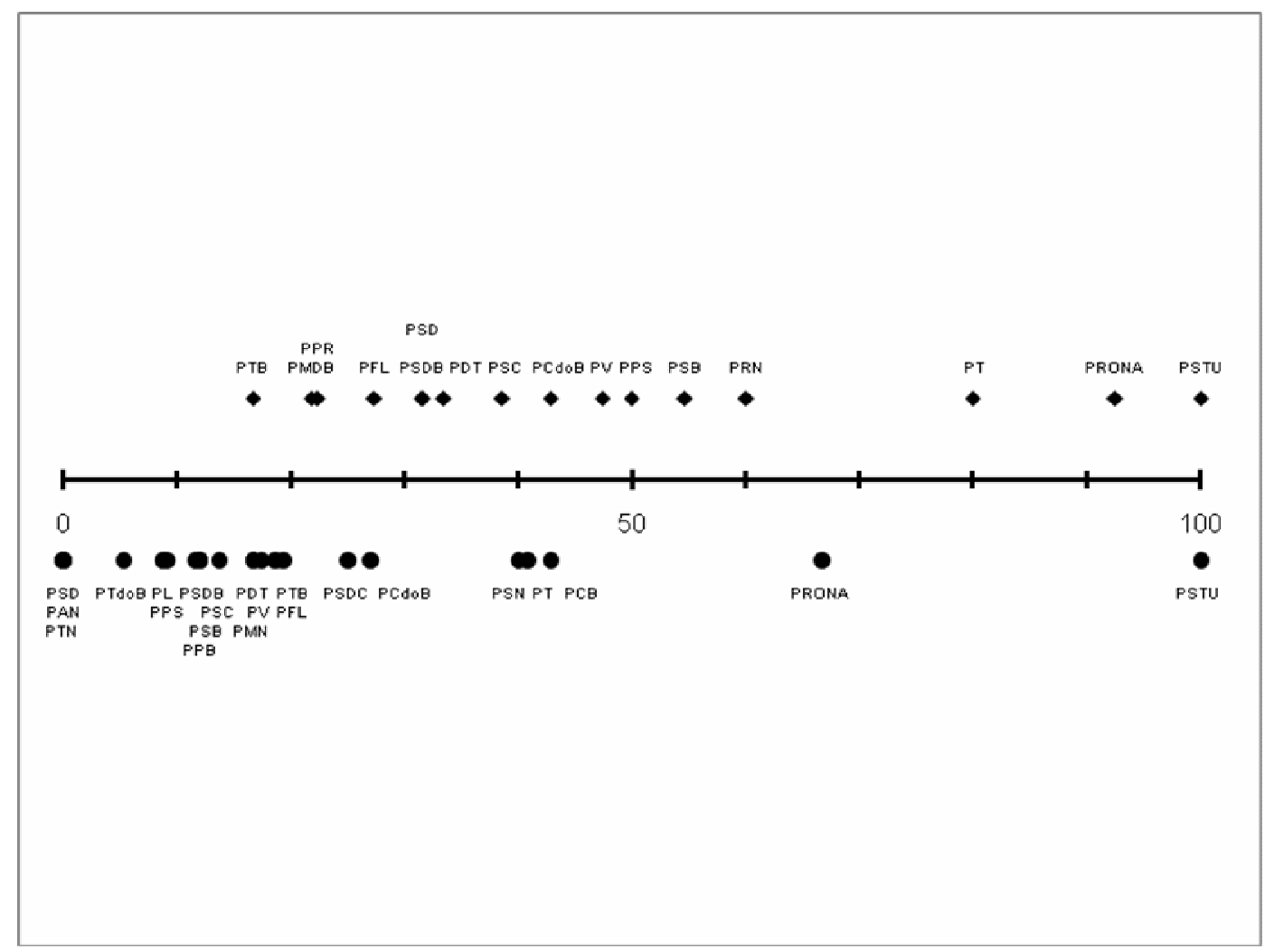

Fonte: Elaboração dos autores com dados do TSE.

No Gráfico 1, quanto mais próximo do valor 100 no eixo, mais congruentes foram as alianças do partido nas eleições majoritárias que participou. Ao contrário, quanto mais distante, maior é a porcentagem de alianças não congruentes firmadas pelo partido nas eleições estaduais. Em outras palavras, o partido que estiver no ponto 100 do eixo, em todos os estados onde disputou as eleições majoritárias, não se coligou com partidos adversários nas eleições presidenciais.

Assim, do lado direito do eixo estão os partidos que mais se aproximariam em 1994 e 1998 da obrigação estabelecida a partir de 2002. No extremo oposto estão os partidos muito distantes da prática da verticalização desenhada pelo TSE para as eleições 2002. Nas eleições de 1998, PSD, PAN e PTN não estabeleceram nos estados nenhuma aliança congruente com a aliança nacional, ou seja, em todos os estados em que participaram das eleições para governador, participaram de coligações com partidos adversários ao cargo de presidente da República. O PSTU 
representa o oposto: nas duas eleições, de 1994 e 1998, quando o partido disputou as eleições para governador, não se aliou a nenhum adversário ao cargo de presidente da República. Foi, portanto, o único partido a formar coligações com o perfil estabelecido judicialmente.

Tomados os dados das duas eleições simultâneas no período pós. democratização, podemos dizer que havia um padrão de coligações partidárias: as coligações estaduais eram assimétricas em relação às coligações nacionais, ou seja, as disputas para os governos estaduais seguiam uma lógica própria independente das disputas para a presidência da República.

Com a decisão do TSE, bastava agora dizer aos partidos que tudo o que haviam feito até então, em termos de coligações políticas, não contribuirá em nada para o fortalecimento do sistema partidário, tão necessário para o bom funcionamento democrático. E que, em quatro meses, deveriam adotar uma prática mais saudável para o país, de acordo com a determinação de um ator externo ao sistema político-partidário.

Não é de estranhar que os partidos se incomodaram com o remédio amargo e decidiram sair em busca de novas consultas e tratamentos. Três frentes simultâneas de ações foram abertas, combinando diferentes estratégias: 1) estratégia judicial, acionando o STF para reformar a decisão do TSE; 2) estratégia preventiva, acionando o TSE com várias consultas para sanar qualquer dúvida, evitando uma ação de impugnação futura, caso a nova regra permanecesse; 3) estratégia refratária, reformando a Constituição para reverter as bases jurídicas da decisão, recusando-se a aceitar a decisão do TSE.

Tudo ocorreu faltando menos de quatro meses para as convenções partidárias e oito meses para as eleições de 2002.

$\mathrm{Na}$ primeira estratégia, duas ADINs acionaram o STF praticamente ao mesmo tempo. A primeira foi proposta em conjunto por PT, PCdoB, PL, PSB e PPS (2626). A segunda foi assinada apenas pelo PFL (2628). A lógica era tentar eliminar os danos políticos causados pela decisão judicial por intermédio do próprio judiciário.

Entretanto, o STF não aceitou esse papel e, com uma maioria não muito expressiva (sete a quatro), decidiu não reconhecer as ADINs, ou seja, não decidiu o mérito da questão. A maioria dos ministros entendeu que não caberia ao STF decidir sobre a decisão do TSE, órgão responsável e supremo para decidir sobre a organização da competição política.

A segunda estratégia, preventiva, veio pelo receio de que, mantendo-se a norma da verticalização, as alianças e os candidatos poderiam ser vítimas de tentativas de impugnação de suas candidaturas por qualquer brecha deixada em aberto.

Dentre as várias consultas, uma produziu um novo momento de tensão entre 
os partidos e seus candidatos. Perguntou-se sobre a possibilidade de um partido que não tivesse lançado candidato à presidência da República e também não participasse de nenhuma coligação para essa eleição firmar alianças com outros partidos para concorrer apenas às eleições estaduais ${ }^{9}$.

A Assessoria Especial da Presidência (Aesp) do TSE respondeu negativamente a essa pergunta. Defendia que, se um partido não tivesse lançado candidato nem participado de aliança para a disputa presidencial, só poderia se coligar para as disputas estaduais com partidos em mesma situação, ou seja, que também não tivessem lançado candidatos à presidência.

Caso a posição da Aesp fosse a posição assumida pelo TSE, os partidos que não lançassem candidatos à presidência teriam uma enorme restrição nas opções políticas para celebrar alianças estaduais, pois, poderiam coligar-se apenas com partidos que também não participassem da disputa presidencial. Essa restrição só não seria maior se o partido decidisse participar da disputa presidencial - suas opções ficariam limitadas aos partidos coligados nessa disputa.

Os ministros do TSE decidiram abrandar a tese da verticalização e não acataram a interpretação da Aesp, liberando os partidos não participantes das eleições presidenciais a se coligarem nos estados com partidos que nela estivessem participando.

Parece-nos que a mensagem deixada aqui pelos ministros do TSE era que, mesmo para atitudes mais arrojadas, seria preciso uma boa dose de moderação.

A terceira estratégia era a refratária, ou seja, buscava mudar a direção da interpretação judicial pela via legislativa. Das três, essa era a estratégia que abria um maior conflito entre os poderes. Demonstrava claramente a resistência em aceitar a decisão de outro poder e iniciava uma espécie de queda de braço pela legitimidade de regulador da competição político-partidária. Essa se mostraria a estratégia mais bem-sucedida dentre as três.

A tentativa mais rápida de reverter a decisão judicial pela via legislativa veio do Senado federal. No dia seguinte ao da publicação da decisão do TSE, o senador Bernardo Cabral (PFL-AM) apresentou o Projeto de Emenda Constitucional (PEC) 04/02, propondo nova redação ao $\S 1^{\circ}$ do art. 17 da Constituição federal, artigo esse que tinha fundamentado a decisão do TSE pela obrigatoriedade do "caráter nacional" dos partidos.

Onde estava determinado apenas que "é assegurada aos partidos políticos autonomia para definir sua estrutura interna, organização e funcionamento, devendo seus estatutos estabelecer normas de fidelidade e disciplina partidárias", propunha-se uma redação mais detalhada para deixar explícita a não

9 Em 26 de março de 2002, o TSE respondeu a cinco consultas sobre esse tema: 1) 758: apresentada pelo PPB; 2) 759: apresentada pelo senador Romero Jucá; 3) 760: apresentada por PGT, PHS, PSDC, PSL, PST, PTdoB e PTN; 4) 762: apresentada pelo senador Geraldo Melo; 5) 766: apresentada pelo PT. 
obrigatoriedade de vinculação entre as alianças eleitorais nacionais, estaduais ou municipais.

A intenção era que a nova redação entrasse em vigor já para as eleições de 2002. Para tanto, seu processo de aprovação, normalmente demorado devido às exigências de maiorias parlamentares qualificadas, foi acelerado ao máximo. A PEC passou pelos procedimentos legislativos obrigatórios a toque de caixa.

A proposta foi aprovada em segundo turno no Senado federal no dia 4 de junho de 2002, pouco mais de três meses depois de ter sido apresentada. 0 primeiro turno de votação, realizado em maio de 2002, terminou com a aprovação de 60 senadores contra 4 reprovações e 2 abstenções. A margem de vitória do segundo turno não foi diferente: 57 votos a favor, 5 contra e 1 abstenção.

Aprovada no Senado, a medida passou para a Câmara ${ }^{10}$, mas já não havia tempo hábil nem condições políticas para sua aprovação naquele mesmo ano, visto que o prazo para o registro dos candidatos e coligações seria encerrado em 30 de junho.

Passado o afogadilho, a Câmara priorizou outras matérias e temas, a legislatura já era outra e, em um novo governo, ademais, as próximas eleições viriam apenas em quatro anos.

Sem entrar nas minúcias dos acontecimentos, a emenda constitucional acabou sendo aprovada pela Câmara apenas em fevereiro de $2006^{11}$. Como se vê, a celeridade vista no Senado ficou longe da Câmara. O fato é que a PEC apresentada em fevereiro de 2002 foi aprovada pelas duas casas e publicada em março de 2006, como Emenda Constitucional 52, sem que qualquer alteração tenha sido feita em sua redação original ${ }^{12}$.

Quando de sua aprovação, já estávamos diante de novas eleições proporcionais e majoritárias. Novamente, o TSE e o STF seriam chamados para decidir sobre a simetria das alianças partidárias para as eleições nacionais e estaduais.

Próximo do final do ano de 2005, o PSL (Partido Social Liberal) ingressou com uma consulta (1185) ao TSE para que esse se manifestasse sobre a manutenção ou não da verticalização. Um ponto a destacar é a necessidade de uma nova consulta para a confirmação da regra em vigência, o que, no mínimo, é indício de insegurança jurídica. Como a verticalização tinha sido fruto de uma interpretação do TSE que não se sustentava claramente em decisões anteriores - e como, até aquele momento, não havia qualquer alteração na legislação eleitoral sobre as

10 Na Câmara dos Deputados, ela tramitou como PEC 548/02.

11 Vale apenas lembrar que as sucessivas crises envolvendo denúncias de compra de voto, "caixa dois" em campanha e desvio de dinheiro público para o caixa dos partidos, levaram o Congresso a mergulhar, durante quase toda a legislatura de 2003-2006, em CPIs e processos de cassação de mandatos.

12 O resultado da votação na Câmara dos Deputados foi o seguinte: Primeiro Turno (25/01/06): SIM: 343. NÃO: 143. Abstenção: 1. Segundo Turno (08/02/06): SIM: 329. NÃO: 142. Abstenção: 0. 
coligações, uma nova busca pelo TSE fazia sentido. Se a verticalização foi fruto de uma interpretação original, uma nova interpretação poderia revogá-la.

A composição da corte tinha sofrido uma completa alteração. Nenhum ministro que havia tomado a decisão em 2002 estava presente no Tribunal do segundo semestre de 2005 e no primeiro de 2006. As expectativas de que a verticalização não seria sustentada pela nova corte eram grandes.

Essa expectativa alimentava-se, basicamente, pelos posicionamentos anteriores do ministro Marco Aurélio de Mello a respeito do tema. De todos os ministros, ele era o único que havia analisado o tema como ministro do STF em 2002. Na ocasião, defendeu claramente que essa regra feria a liberdade dos partidos e que, portanto, a decisão judicial deveria ser reformada.

A consulta só foi respondida em março de 2006 e, contrariando alguns otimistas interessados no tema, o TSE manteve a regra da verticalização.

A tese vencedora foi, no mínimo, curiosa. Defenderam que a regra da verticalização tinha, de fato, ferido a autonomia dos partidos como consequência de uma atuação mais arrojada do TSE. Apesar disso, havia um entendimento de que, se não houve, até um ano antes das eleições, alterações na norma ou na interpretação anterior, a consulta que ali se respondia não poderia dar orientação diversa daquela que regeu as eleições anteriores. Se assim fizessem, estariam desrespeitando a regra constitucional da anualidade para legislação eleitoral.

$\mathrm{O}$ argumento é interessante na medida em que assume que decidir sobre as coligações partidárias naqueles termos é estabelecer nova norma e que, em razão disso, deve-se respeitar o limite de um ano antes da realização das eleições a fim de garantir certa estabilidade das normas e, acima de tudo, segurança jurídica para os participantes do processo.

O posicionamento jurídico e teórico dessa corte de 2006 revela-se completamente contrário ao posicionamento da corte de quatro anos antes. Vale destacar que, além de defender a restrição da autonomia partidária na confecção de coligações, aquele tribunal entendeu que a interpretação não produziu nova norma, apenas regulamentou o que já estava definido em lei. Por esse entendimento é que a regra da verticalização se impôs a menos de oito meses das eleições.

E foi exatamente por haver essa divergência de posicionamentos que a regra da verticalização se repetiu nas eleições de 2006. Se a corte buscava um posicionamento mais moderado, acabou por garantir a validade da posição mais arrojada.

Respondida essa consulta, veio o período de maior tensão política. Aliás, ao longo da espera pela decisão do TSE, o otimismo daqueles que desejavam o fim da regra da verticalização foi cedendo espaço para a desconfiança. Só aí a Câmara se apressou para aprovar a PEC, em uma tentativa de reformar a decisão judicial pela 
via legislativa, resgatando com força a estratégia refratária de 2002.

A consulta foi respondida pelo TSE em 3 de março de 2006, e a Emenda Constitucional foi publicada cinco dias depois. Como já foi dito, seu texto foi aprovado sem qualquer modificação pelo plenário - isso incluiu o parágrafo $2^{\circ}$, que determinava a validade da nova norma já para as eleições de 2002. A pressa para a aprovação da matéria foi tamanha que até mesmo esse problema de anacronismo permaneceu no texto. Se a Câmara tentasse corrigir o parágrafo da Emenda Constitucional, o texto precisaria passar novamente pelos trâmites legislativos para ser aprovado no Senado Federal. A opção foi aprovar o texto sem qualquer mudança.

Aprovado esse texto, os parlamentares esperavam ter enterrado de vez a obrigatoriedade da simetria para as coligações. Se o texto já desobrigava os partidos para as eleições de 2002, para as eleições que se avizinhavam não restavam dúvidas quanto ao fim da verticalização.

Assim que o texto foi publicado, o Conselho Federal da OAB (Ordem dos Advogados de Brasil) impetrou uma ADIN junto ao STF, questionando a validade do novo texto constitucional para as eleições de 2006. O argumento em debate foi, mais uma vez, o princípio da anualidade para a legislação eleitoral (CF, art. 16). A rigor, não houve uma defesa da inconstitucionalidade do texto da EC 52; apenas se argumentava que a norma não mais poderia regular as próximas eleições, visto haver menos de nove meses para a sua realização.

O STF, mesmo depois de uma ampla mobilização dos partidos para que não fosse acatado o argumento da OAB, acabou por determinar que os efeitos produzidos pela EC 52 alteravam substantivamente a legislação eleitoral em vigor, estando ela, assim, impedida de entrar em vigor no ano eleitoral.

O mais interessante é que a norma da verticalização foi o resultado de uma interpretação judicial da lei eleitoral feita em ano eleitoral, e todas as tentativas posteriores para reformá-la foram vetadas pelo judiciário exatamente em respeito aos limites constitucionais para a alteração da lei eleitoral em ano de eleições.

Em resumo, temos o seguinte, desde que as eleições nacionais e estaduais se tornaram coincidentes, houve quatro eleições: 1994, 1998, 2002 e 2006. Nas duas primeiras, os partidos políticos imprimiram um padrão de comportamento para as alianças partidárias que se orientava pela assimetria entre os diferentes estados e a disputa presidencial. Nas eleições seguintes, 2002 e 2006, por uma imposição judicial, esse padrão foi forçado a alterar-se em nome de um fortalecimento dos partidos em âmbito nacional.

Quais os efeitos do quadro apresentado? Quais conclusões podemos tirar? Para avançarmos nessa questão, seguiremos dois caminhos. Primeiro, mensurar o impacto da regra da verticalização nas eleições: essa regra produziu o efeito 
desejado pelos ministros, a nacionalização dos partidos? Segundo, entender os efeitos da judicialização da competição político-eleitoral.

\section{Conclusão}

A participação mais ativa da cúpula da justiça eleitoral na organização e na gestão da competição política no Brasil revela seu perfil oscilante e demonstra o distanciamento da prática política dos desejos emanados das cortes judiciais.

Tendo em mãos o diagnóstico de parte da literatura política sobre o perfil dos partidos políticos brasileiros. MAINWARING, 2001-, a maioria dos sete ministros do TSE impôs uma regra corretiva de possíveis defeitos advindos desse perfil. Avaliando os efeitos na competição política dessa nova regra, porém, podemos afirmar que a esperada nacionalização cedeu lugar para uma maior regionalização dos partidos.

A tendência dos partidos foi abandonar formalmente a disputa nacional, construindo nos estados plataformas informais para os candidatos à presidência. Entre a opção de ingressar em uma coligação para presidente restringindo as possibilidades de alianças e a opção de manter-se próximo de suas bases regionais não ingressando em uma coligação nacional, a maioria dos partidos escolheu a segunda opção. Dessa lógica surgiram nos estados diversas "coligações brancas", que serviram apenas de palanques informais para os candidatos a presidente da república, que neles subiam conforme a conveniência e o desenrolar da disputa (CARVALHO, 2006). 


\section{GRÁFICO 2}

Evolução do número de partidos disputando as eleições presidenciais, disputando exclusivamente as eleições estaduais e os que conquistaram representação na Câmara dos Deputados

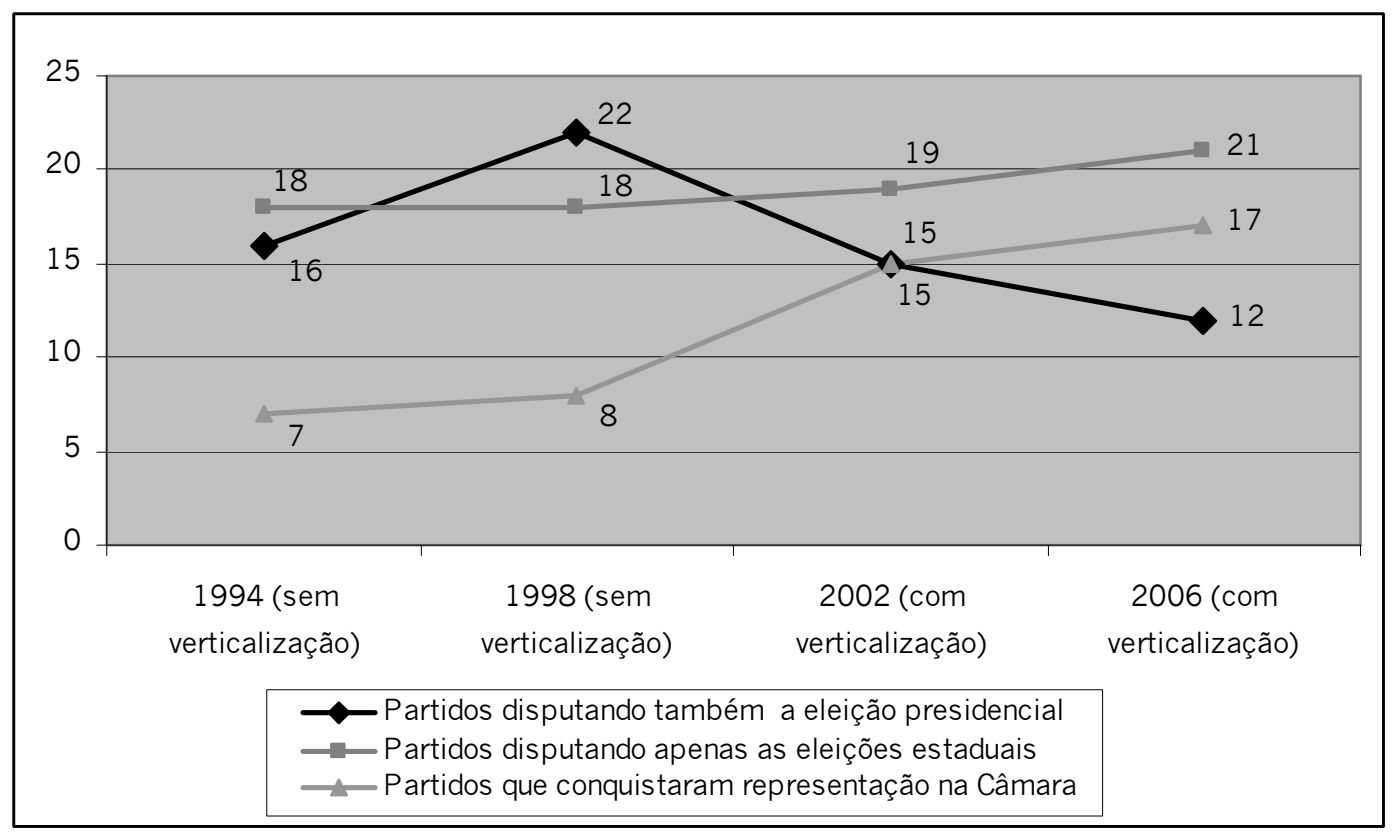

Fonte: TSE e Nicolau <http://jaironicolau.iuperj.br>.

O Gráfico 2 mostra a evolução da participação dos partidos nas eleições de 1994, 1998, 2002 e 2006, destacando quantos partidos, dentre todos os que disputaram as eleições, participaram também das eleições presidenciais, quantos participaram exclusivamente de eleições estaduais e quantos partidos conquistaram o direito à representação na Câmara dos Deputados.

O crescimento dos partidos que disputaram exclusivamente as eleições estaduais foi acompanhado pelo decréscimo dos partidos que disputaram, isoladamente ou em coligações, as eleições presidenciais. Esse é um indício bastante forte de que, quando os partidos foram colocados diante de duas opções, alianças nacionais ou estaduais, ficaram com a segunda.

Os efeitos da verticalização para a competição política foram em alguma medida em sentidos opostos quando comparamos o efeito nas disputas presidenciais e para governador do estado. De acordo com Cortez (2009), a construção de candidaturas presidenciais passa por um processo de nacionalização através da criação de palanques estaduais. Esses palanques são construídos por 
meio da disputa para o governo estadual. Grosso modo, os partidos que disputavam as eleições presidenciais apoiavam candidatos de outros partidos em troca de apoio em nível nacional.

A verticalização dificultou esse processo ao restringir as escolhas permitidas aos partidos políticos. Dessa forma, houve um aumento significativo do número de candidaturas no nível estadual, o que, dificultou o quadro de estabilização dos sistemas partidários estaduais.

No tocante às eleições presidenciais, o efeito foi aumentar para os partidos os custos da disputa. Este efeito foi mais sentido em 2006, pois já havia uma antecipação por parte das elites, o que resultou na diminuição de partidos disputando a presidência.

Isso não significa que esses partidos se ausentaram da campanha presidencial, mas, como mostrou Carvalho (2006), significa que a regra judicial jogou as alianças para a informalidade, fazendo com que, em cada estado, os candidatos à presidência continuassem a subir em palanques de partidos nacionalmente adversários.

Avançando nos resultados eleitorais, podemos afirmar que se manteve um alto índice de partidos com representação no parlamento - superior, aliás, ao período em que não havia a regra da verticalização (Gráfico 2) - e que, além disso, cresceu o número efetivo de partidos (Tabela 1 ).

TABELA 1

Representação na câmara dos deputados: número efetivo de partidos (NE)

\begin{tabular}{|c|c|}
\hline Ano & (NE) \\
\hline 1994 & 8,1 \\
\hline 1998 & 7,1 \\
\hline 2002 & 8,5 \\
\hline 2006 & 9,3 \\
\hline \multicolumn{2}{|c|}{ Fonte: LEEX <http://www.ucam.edu.br/leex/> } \\
\hline
\end{tabular}

A manutenção dos elevados índices de fragmentação nas eleições legislativas mostra que não houve efeito significativo da verticalização no formato das disputas presidenciais. Esse resultado é semelhante a trabalhos que apontam para um processo de consolidação do sistema partidário brasileiro. Braga (2006) mostra como a estabilização do sistema partidário brasileiro está centrada nas disputas majoritárias. A elevada fragmentação está mais relacionada com o "federalismo partidário" brasileiro (NICOLAU, 1996). 
Se o raciocínio estiver correto, o aumento dessa fragmentação pode ser atribuído à maior regionalização das disputas partidárias, diferentemente do que os ministros idealizaram.

Se a metodologia adotada neste artigo para a mensuração do poder estiver adequada, podemos dizer que a judicialização da política do Brasil, ao menos no caso analisado, ocorreu durante a competição política. Não alterou decisões políticas majoritárias finais sobre políticas públicas, mas impactou um momento anterior à formação dessas maiorias.

Não estamos diante de um caso em que a vontade majoritária foi impedida de fazer valer suas preferências freadas pelo judiciário. A judicialização, aqui, ocorreu sem nem mesmo haver um litígio entre as partes. Como ela foi estabelecida após a resposta a uma Consulta não podemos dizer que estávamos diante de um processo judicial comum. Para que o instrumento da Consulta seja utilizado é necessário apenas que exista uma dúvida de um competidor em relação aos detalhes da regra. Não há aqui teses distintas em confronto. Há apenas uma pergunta.

Do ponto de vista jurídico, podemos dizer que a Consulta é uma peça processual precária. Não faz a coisa julgada, apenas indica uma possível interpretação do julgador em relação às regras vigentes. Não há nem mesmo um vínculo obrigatório da resposta dada a uma consulta e uma decisão judicial futura sobre um caso concreto idêntico.

Outro elemento que reforça a tese de que a judicialização se deu mesmo sem haver uma posição contramajoritária de seus membros, é o fato de que a verticalização foi criada pelo TSE sem que o tema estivesse sequer em debate no Congresso Nacional. Ou seja, não é possível avaliar a posição majoritária dos atores políticos, o debate não estava posto. O que havia era uma competição política coordenada de modo distinto da orientação judicial. O posicionamento dos atores políticos em sentido contrário à verticalização foi resultado do posicionamento dos atores judiciais envolvidos.

A decisão judicial, aqui, não surgiu como o resultado de uma decisão política final. Ao contrário, incluiu o tema na agenda política forçando uma decisão final do executivo e do legislativo. Resultado disso foi que a judicialização da competição política acabou por constitucionalizar parte fundamental desse jogo, o padrão de formação de coalizões.

Há uma tese corrente de que as decisões judiciais em matéria eleitoral apenas ocupariam um espaço aberto pela inconstância do legislador. Assim, um maior ativismo dos ministros do TSE poderia ser entendido como resultado da necessidade de sanar as brechas da legislação ou mesmo as suas dubiedades. 
"A instabilidade da legislação também tem estimulado a pluralidade de decisões. (...) Mudanças constantes dificultam o desenvolvimento de entendimentos uniformes e a criação de padrões de comportamento. Como, contudo, a legislação é modificada a cada eleição, torna-se difícil a sedimentação de regras seguras sobre as diferentes etapas do processo eleitoral. Assim, durante o processo, quando contestadas, leis podem ser modificadas pelo TSE." (SADEK, 1995, p. 63).

Acreditamos que essa conclusão deva ser, no mínimo, ponderada. Por ora, o estudo da decisão sobre a verticalização nos revelou um processo contrário do suposto por Sadek (1995). A mudança do comportamento judicial não veio pela mudança da legislação, ou por sua deficiência; ao contrário, a mudança da legislação só se tornou necessária por uma mudança de posicionamento da justiça eleitoral. A decisão judicial não foi contramajoritária, a decisão política é que foi refratária em relação à preferência judicial.

O Quadro 1 tenta representar esse movimento, demonstrando, ainda, como imperou no legislativo a estratégia refratária já referida aqui:

\section{QUADRO 1 \\ Evolução resumida da legislação e das decisões judiciais sobre as regras das coligações partidárias}

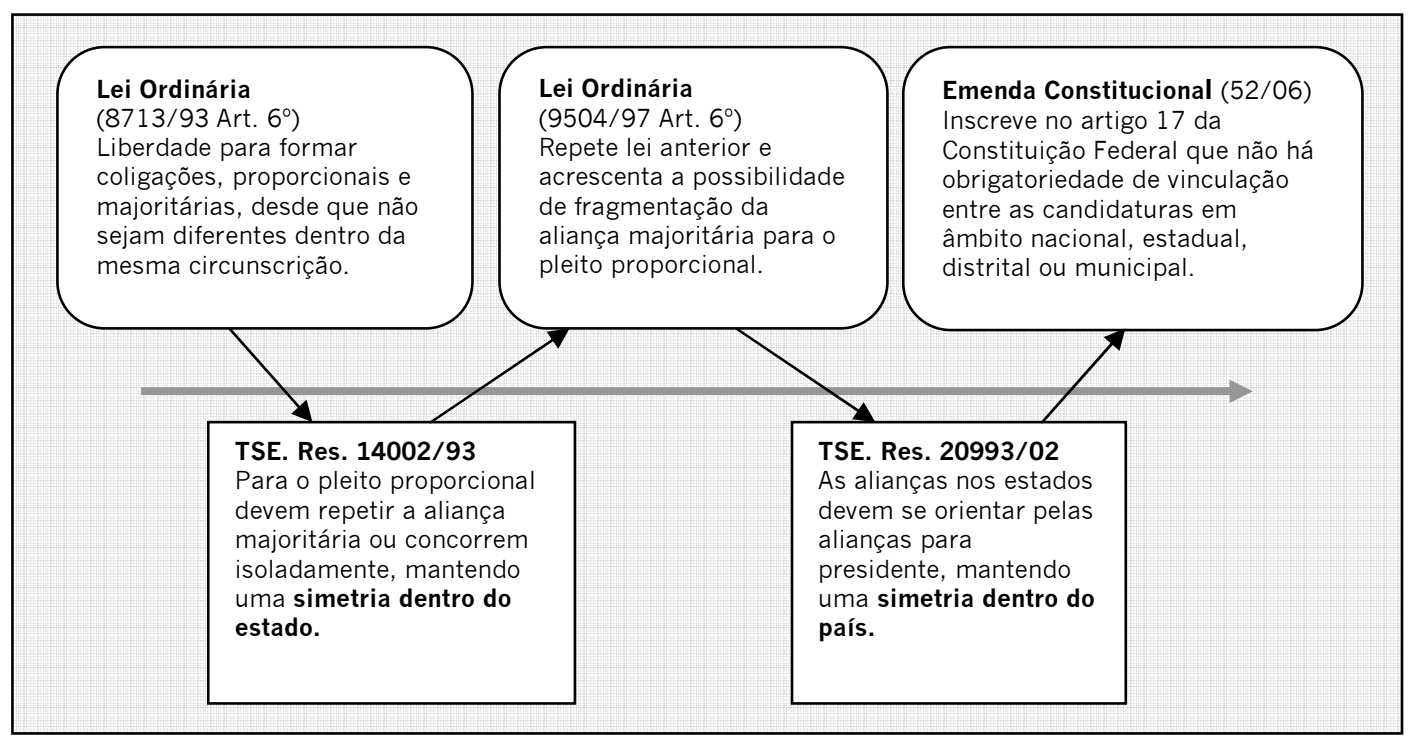

Foi em refração às diferentes interpretações judiciais sobre um mesmo dispositivo legal que a legislação se transformou. O que há não é uma simples adequação do texto às interpretações judiciais, mas um processo de reforma da 
decisão judicial para se proteger de suas futuras interpretações. O que acabou por conduzir os partidos a um bunker mais seguro, a Constituição Federal.

O tema da verticalização das coligações revelou tensões para dentro e para fora na cúpula da justiça eleitoral. Seus debates internos e a reação dos seus "clientes" ficaram longe do equilíbrio e da definição de consensos mínimos.

O modelo arrojado adotado pelos ministros do TSE produziu a constitucionalização de uma prática política que até então estava regulada por leis ordinárias. Do ponto de vista estratégico, essa decisão mostrou-se equivocada no sentido da preservação de suas preferências relativas ao padrão ideal da competição política. Ao reinterpretar a legislação relativa à competição eleitoral, estabelecendo novas bases para a competição partidária, o TSE colocou a política para além da curva de indiferença do poder legislativo. A percepção por parte dos legisladores é que o novo status quo representou uma ameaça institucional. Dessa forma, podemos entender a estratégia dos legisladores de constitucionalizar práticas que, no limite, não representam princípios fundamentais. A emenda constitucional expressou a defesa da autonomia dos legisladores na regulação da atividade política.

Trata-se da incorporação de um preceito legislativo estranho ao sentido da Carta Magna. Assim, a questão da regulamentação das coligações eleitorais exemplifica uma mudança de status jurídico de uma lei. Constitucionalizou-se a competição político-partidária.

O fator explicativo para esse processo é a reação político-partidária frente a um comportamento arrojado da justiça eleitoral. Para se proteger dos efeitos políticos de um agente "estranho" à política, inclui-se no texto constitucional especificidades do padrão de comportamento dos partidos durante um processo típico da competição política, o momento eleitoral.

A constitucionalização da prática política não foi aqui, portanto, o resultado de uma mera opção política, mas a reação ao avanço do judiciário sobre os padrões definidos historicamente pela própria prática partidária.

Por fim, um efeito que merece destaque é o desdobramento dessa estratégia refratária. Ao mesmo tempo em que constitucionalizou uma regra típica do jogo político corriqueiro, ela pode ter aberto o caminho para o enfrentamento político entre esses poderes ${ }^{13}$, criando uma animosidade pouco saudável para o equilíbrio das regras do jogo democrático, tão importantes para a longevidade de um sistema de segurança mútua que permita a estabilidade da competição pelo poder político.

13 A hipótese é que, em outras decisões tomadas pelo TSE, como a fidelidade partidária e o fim da cláusula de barreira, a estratégia adotada pelo Parlamento tende a ser a mesma: alterar a decisão do TSE por uma "contradecisão" legislativa. Para uma análise desses casos, ver Marchetti (2008a). 


\section{Referências Bibliográficas}

ARANTES, R. Ministério Público e Política no Brasil. São Paulo: Sumaré/Educ, 2002.

Constitucionalism, the Expansion of Justice and the Judicialization of Politics in Brazil. In: Sieder, R., Schjolden, L. e Angell, A. (orgs.). The Judicialization of Politics in Latin America. New York: Palgrave, 2005.

ARANTES, R. e KERCHE, F. "Judiciário e Democracia no Brasil". Novos Estudos, v.54, 1999.

BACHRACH, P. e BARATZ, M. "Two Faces of Power". American Political Science Review, v.56, nº 4, 1962.

BRAGA, M. S. O Processo Partidário-Eleitoral Brasileiro: Padrões de Competição Política (1982-2002). São Paulo, Humanitas/FAPESP, 2006.

CAREY, J. e SHUGART, M. "Incentives to Cultivate a Personal Vote: A Rank Order of Electoral Formula". Electoral Studies, v.14, n² 4, 1995.

CARVALHO, E. "Em busca da Judicialização da Política no Brasil: Apontamentos para uma nova Abordagem". Revista de Sociologia e Política, v.23, 2004.

CARVALHO, E. e OLIVEIRA, V. A judicialização da política no Brasil: Conceitos e Paradoxos. Um tema em aberto. Trabalho apresentado no $3^{\circ}$ Encontro da Associação Brasileira de Ciência Política. Painel Temático "Instituições Políticas" Niterói, mimeo, 2002.

CARVALHO, V. Partidos e Eleições no Brasil: Razões e Efeitos da "Verticalização" das Coligações Eleitorais. Tese de mestrado em Ciências Sociais: Política, PUC-SP, São Paulo, 2006.

CASTRO, M. "O Supremo Tribunal Federal e a Judicialização da Política". Revista Brasileira de Ciências Sociais, v.12, nº 34, 1997.

CORTEZ, R. Eleições Majoritárias e Entrada Estratégica no sistema partidário-eleitoral brasileiro. Tese de doutorado em Ciência Política. USP, São Paulo, 2009.

COUTO, C. e ARANTES, R. "Constituição, Governo e Democracia no Brasil". Revista Brasileira de Ciências Sociais, São Paulo, v.21, nº 61, 2006.

DAHL, R. "The Concept of Power". Behavioral Science, v.2, 1957.

"A Critique of the Ruling-Elite model". American Political Science Review, v.52, n², 1958. 
Who Governs? Democracy and Power in an American City. New Haven: Yale University Press, 1961.

FEREJOHN, J. "Judicializing Politics, Politicizing Law". Law and Contemporary Problems, v.65, n³, 2002.

FIGUEIREDO, A. e LIMONGI, F. Executivo e Legislativo na Nova Ordem Constitucional. Rio de Janeiro. FGV/Fapesp, 1999.

KOERNER, A. Direito e Modernização Periférica - Por uma Análise Sócio-Política do Pensamento Jurídico Constitucional Brasileiro Pós-1988. Trabalho apresentado ao Grupo de Trabalho Dilemas da Modernização Periférica, XXIX Encontro Anual da Associação de Pós-Graduação e Pesquisa em Ciências Sociais - Anpocs. Caxambu, Mimeo, 2005.

MANIN, B. The Principles of Representative Government. New York: Cambridge University Press, 1997.

MARCH, J. e OLSEN, J. "The New Institutionalism: Organizational Factors in Political Life". American Political Science Review, v.78, n 3, 1984.

MARCHETTI, V. "O Controle Constitucional da Atividade Legislativa do Executivo: Brasil e Argentina Comparados". Revista Teoria \& Sociedade: Revista dos Departamentos de Ciência Política e de Sociologia e Antropologia da UFMG. Belo Horizonte, v.12, $n^{\circ} 2,2004$.

Poder Judiciário e Competição Política no Brasil: uma análise das decisões do TSE e do STF sobre as regras eleitorais. Tese de doutorado em Ciências Sociais: Política. PUC-SP, São Paulo, 2008a.

v. $51, \mathrm{n}^{\circ} 4,2008 \mathrm{~b}$.

"Governança Eleitoral: o modelo brasileiro de Justiça Eleitoral". Dados,

MIGUEL, L. F. "Representação política em 3D: elementos para uma teoria ampliada da representação política". Revista Brasileira de Ciências Sociais, v.18, nº 51, 2003.

MILLS, W. The Power Elite. Oxford: Oxford University Press, 1956.

NICOLAU, J. Democracia e Multipartidarismo. Rio de Janeiro: FGV, 1996.

OLIVEIRA, V. "Judiciário e Privatizações no Brasil: Existe uma Judicialização da Política?" Dados, v.48, n³ 2005.

RIKER, W. "Some Ambiguities in the Notion of Power". American Political Science Review, v.58, ํo 2, 1964. 
SADEK, M. T. A Justiça Eleitoral e a Consolidação da Democracia no Brasil. São Paulo: Konrad Adenauer, 1995.

TATE, C. N. e VALLINDER, T. The Global Expansion of Judicial Power. New York: New York, University Press, 1995.

TATE, C. N. When the Courts Go Marching. In: TATE, C. N. e VALLINDER, T. The Global Expansion of Judicial Power. New York: New York University Press, 1995.

TAYLOR, M. "Veto and Voice in the Courts - Policy Implications of Institutional Design in the Brazilian Judiciary". Comparative Politics, abril, 2006. . Judicial Independence. Mimeo, 2007. p.229-257, 2007a. "O Judiciário e as Políticas Públicas no Brasil". Dados, v.50, n² 2, VALLINDER, T. Why the Expansion of Judicial Power?, In: TATE, C. N. e VALLINDER, T. The Global Expansion of Judicial Power. New York, New York University Press, 1995.

VIANNA, L. W. (et al). A Judicialização da Política e das Relações Sociais no Brasil. Rio de Janeiro: Revan, 1999.

VIANNA, L. W. e BURGOS, M. "Entre Princípios e Regras: Cinco Estudos de Caso de Ação Civil Pública". Dados, v.48, n² 4, 2006.

Vitor Marchetti - vitor.marchetti@yahoo.com.br

Rafael Cortez - cortezrp@yahoo.com.br

Recebido para publicação em fevereiro de 2009.

Aprovado para publicação em agosto de 2009. 